\title{
Quantitative Proteomic Study of Human Lung Squamous Carcinoma and Normal Bronchial Epithelial Acquired by Laser Capture Microdissection
}

\author{
Xu Yan, ${ }^{1,2}$ Cao Lan-Qin, ${ }^{3}$ Jin Long-Yu, ${ }^{4}$ Chen Zhu-Chu, ${ }^{1}$ Zeng Gu-Qing, ${ }^{5}$ Tang Can-E, \\ Li Guo-Qing, ${ }^{6}$ Duan Chao-Jun, ${ }^{1}$ Peng Fang, ${ }^{1}$ Xiao Zhi-Qiang, ${ }^{1}$ and Li Cui ${ }^{1}$ \\ ${ }^{1}$ Key Laboratory of Cancer Proteomics of Chinese Ministry of Health, Xiangya Hospital, Central South University, \\ Changsha 410008, China \\ ${ }^{2}$ Judicial Police General Hospital, Changsha 410004, China \\ ${ }^{3}$ Department of Gynecology and Obstetrics, Xiangya Hospital, Central South University, Changsha 410008, China \\ ${ }^{4}$ Department of Cardiothoracic Surgery, Third Xiangya Hospital, Central South University, Changsha 410013, China \\ ${ }^{5}$ Department of General Introduction to Surgery, School of Medicine, University of South China, Hengyang 421001, China \\ ${ }^{6}$ Department of Biology, School of Pharmacy and Life Science, University of South China, Hengyang 421001, China
}

Correspondence should be addressed to Li Cui, licuipwb@yahoo.com.cn

Received 8 June 2011; Revised 30 November 2011; Accepted 1 December 2011

Academic Editor: Kapil Mehta

Copyright (C 2012 Xu Yan et al. This is an open access article distributed under the Creative Commons Attribution License, which permits unrestricted use, distribution, and reproduction in any medium, provided the original work is properly cited.

\begin{abstract}
Objective. To investigate the differential protein profile of human lung squamous carcinoma (HLSC) and normal bronchial epithelium (NBE) and provide preliminary results for further study to explore the carcinogenic mechanism of HLSC. Methods. Laser capture microdissection (LCM) was used to purify the target cells from 10 pairs of HLSC tissues and their matched NHBE, respectively. A stable-isotope labeled strategy using iTRAQ, followed by 2D-LC/Q-STAR mass spectrometry, was performed to separate and identify the differential expression proteins. Results. A total of 96 differential expression proteins in the LCM-purified HLSC and NBE were identified. Compared with NBE, 49 proteins were upregulated and 47 proteins were downregulated in HLSC. Furthermore, the expression levels of the differential proteins including HSPB1, CKB, SCCA1, S100A8, as well as S100A9 were confirmed by western blot and tissue microarray and were consistent with the results of quantitative proteomics. Conclusion. The different expression proteins in HLSC will provide scientific foundation for further study to explore the carcinogenic mechanism of HLSC.
\end{abstract}

\section{Introduction}

Lung cancer ranks the first in the morbidity and mortality of human malignancies and keeps the leading position of all common malignant tumors worldwide. Histopathologically, lung cancers are classified into small cell lung cancer and nonsmall cell lung cancer. The latter is further classified into squamous cell carcinoma, adenocarcinoma, and large cell caicinoma, according to its morphologic patterns. Among which, squamous cell carcinoma is the most common, which accounts for $40 \%-70 \%$ [1]. Squamous cell carcinoma originates from the bronchial epithelial cell. Currently, the mechanism of the initiation, development, and dissemination of human lung squamous carcinomas (HLSCs) is still unclear.
Proteomics provides a new opportunity to reveal the carcinogenic mechanism of HLSC. The comparative proteomics compares the tumor and its origin tissue may reflect the carcinogenesis. However, the main obstacle for proteomics analysis is the heterogeneity of the soft tumor tissues. In order to improve the accuracy of the results, it is necessary to purify the target cells from the heterogeneous tissues. Laser capture microdissection (LCM) is one of the best technologies for cell purification [2-6]. The quantitative proteomics is one of the emerging fields for tumor proteomics study; isotope labeling relative and absolute quantification (iTRAQ) is a new technique in quantitative proteomics, which could be used to identify and quantify the protein expression levels and identify the small changes of protein expression in different tissues. 
In this study, LCM was used to purify the target cells from HLSC tissues and matched NBE; iTRAQ followed by 2DLC/Q-STAR mass spectrometry was performed to separate and identify the differential expression proteins in LCMpurified HLSC tissues and matched NHBE.

\section{Materials and Methods}

2.1. Sample Collection, Laser Capture Microdissection, and Protein Extraction. Twenty pairs of HSCL tissues and matched normal bronchial epithelium tissues from the LSCC patients undergoing curative surgery and receiving neither chemotherapy nor radiotherapy were obtained from Department of Cardiothoracic Surgery, The Second Xiangya Hospitals of Central South University, China. The patients signed an informed consent form for the study which was approved by the local ethical committee. Samples were diagnosed by histopathology. 10 pairs of the tissues were used for ITRAQ, and the other 10 pairs of the tissues for Western blotting, respectively. Tissues were frozen in $-70^{\circ} \mathrm{C}$.

LCM was performed with a Leica AS LMD system to purify the interest cells from HSCL tissues and matched NBE tissues as previously described by us. Breifly, frozen sections $(8 \mathrm{~mm})$ from each HLSC and NBE tissues were prepared using a Leica CM 1900 cryostat (Leica) at $-25^{\circ} \mathrm{C}$. The sections were placed on a membrane-coated glass slides (Leica), fixed in 75\% alcohol for $30 \mathrm{~s}$, and stained with $0.5 \%$ violet-free methyl green (Sigma). The stained sections were air-dried and then subjected to LCM.

The microdissected cells were dissolved in lysis buffer (7 M urea, $2 \mathrm{M}$ thiourea, $65 \mathrm{mM}$ DTT, $0.1 \mathrm{mM}$ PMSF) at $4^{\circ} \mathrm{C}$ for $1 \mathrm{~h}$ and then centrifuged at $12000 \mathrm{rpm}$ for $30 \mathrm{~min}$ at $4^{\circ} \mathrm{C}$. The supernatant was collected, and the protein concentration was determined by 2D Quantification kit (Amersham Biosciences). To diminish the effect of sample biological variation on the results of a proteomics analysis, equal amounts of proteins from the microdissected cells of 10 different individuals were pooled to generate one common sample iTRAQ labeling.

2.2. Protein Digestion and Labeling with iTRAQ Reagents. Trypsin digestion and iTRAQ labeling were performed according to the manufacturer's protocol (Applied Biosystems). Briefly, $100 \mu \mathrm{g}$ protein of each pooled sample was reduced and alkylated and then digested overnight at $37^{\circ} \mathrm{C}$ with trypsin (mass spectrometry grade; Promega) and labeled with iTRAQ reagents (Applied Biosystems) as follows: NBE, iTRAQ reagent 113; and HLSC, iTRAQ reagent 115 . The labeled digests were then mixed and dried.

2.3. Off-Line 2D LC-MS/MS. The mixed peptides were fractionated by strong cation exchange (SCX) chromatography on a 20AD HPLC system (Shimadzu) using a polysulfoethyl column $(2.1 \times 100 \mathrm{~mm}, 5 \mu \mathrm{m}, 300 \AA \AA$; The Nest Group Inc.) as previously described by us [7]. Briefly, the mixed peptides were desalted with Sep-Pak Cartridge (Waters), diluted with the loading buffer (10 mM KH2PO4 in 25\% ACN, pH 2.8), and loaded onto the column. Buffer A was identical in composition to the loading buffer, and buffer B was same as buffer A except of containing $350 \mathrm{mM} \mathrm{KCl}$. Separation was performed using a linear binary gradient of $0-80 \%$ buffer $\mathrm{B}$ in buffer $\mathrm{A}$ at a flow rate of $200 \mu \mathrm{l} / \mathrm{min}$ for $60 \mathrm{~min}$. The absorbance at $214 \mathrm{~nm}$ and $280 \mathrm{~nm}$ was monitored, and a total of 30 SCX fractions were collected along the gradient.

Each SCX fraction was dried down, dissolved in buffer C (5\% ACN, 0.1\% FA), and analyzed on Qstar XL (Applied Biosystems) as previously described by us [7]. Briefly, peptides were separated on a reverse-phase $(\mathrm{RB})$ column (ZORBAX 300SB-C18 column, $5 \mu \mathrm{m}, 300 \AA, 0.1 \times 15 \mathrm{~mm}$; Micromass) using a 20AD HPLC system (Shimadzu). The HPLC gradient was $5-35 \%$ buffer D (95\% ACN, $0.1 \% \mathrm{FA})$ in buffer C at a flow rate of $0.2 \mu \mathrm{l} / \mathrm{min}$ for $65 \mathrm{~min}$. Survey scans were acquired from 400 to 1800 with up to 4 precursors selected for MS/MS from $\mathrm{m} / \mathrm{z}$ 100-2000 using a dynamic exclusion of $30 \mathrm{~S}$. The iTRAQ-labeled peptides fragmented under CID conditions to give reporter ions at 113.1 and $1151 \mathrm{Th}$. The ratios of peak areas of the iTRAQ reporter ions reflect the relative abundances of the peptides and, consequently, the proteins in the samples. Larger, sequence-information-rich fragment ions were also produced under these MS/MS conditions and gave the identity of the protein from which the peptide originated.

2.4. Data Analysis. The ProteinPilot 3.0 software program (ABI, USA) was used to perform Protein identification and quantification analysis for the iTRAQ experiment. Identified proteins were grouped by the software to minimize redundancy; all peptides used for the calculation of protein ratios were unique to the given protein or proteins within the group. The protein confidence threshold cutoff for this study is ProtScore 1.3 (unused) with at least one peptide with $95 \%$ confidence. The relative protein abundances were analyzed by the signature ion ratio $(\mathrm{m} / \mathrm{z}, 115 / 113)$ : the ratio $\geq 1.2$ and $\leq 0.8$ as the differential expression proteins.

2.5. Western Blotting. Western blotting was performed in ten pairs of microdissected HLSC and NBE. Briefly, 30-50 $\mu \mathrm{g}$ of purified protein was separated by $10 \%$ SDS-PAGE and transferred to PVDF membrane (Bio-Rad). The blots were incubated for $2 \mathrm{~h}$ at room temperature in TBST (20 mM Tris$\mathrm{Cl}, 140 \mathrm{mM} \mathrm{NaCl}, \mathrm{pH}$ 7.5, 0.05\% Tween-20) containing 5\% skim milk and then were incubated with monoclonal mouse anti-HSPB1 (dilution 1:1000, Abcam), monoclonal rabbit anti-CKB (dilution 1:200, Santa Cruze), polyclonal rabbit anti-human S100A8/A9, and polyclonal mouse anti-human SCCA1 (dilution 1:200, Santa Cruze) overnight at $4^{\circ} \mathrm{C}$. After washing three times in TBST, membranes were incubated with a horse radish peroxidase conjugated secondary antibody (dilution 1:3,000, Amersham Biosciences) for $1 \mathrm{~h}$ at room temperature. The blots were developed using ECL detection reagent and quantitated by densitometry using ImageQuant image analysis system (Storm Optical Scanner). The $\beta$-actin was detected simultaneously as a loading control.

2.6. Tissue Microarray and Immunohistochemistry. The tissue microarray containing 30 lung squamous cell carcinoma, 
TABle 1: The clinicopathological parameters of the 100 tissue specimens.

\begin{tabular}{lc}
\hline Classification & Number \\
\hline Gender & \\
Male & 84 \\
Female & 16 \\
Age & \\
$\geq 55$ & 68 \\
$<55$ & 32 \\
Histological type & \\
Squamous cell carcinoma & 30 \\
High differentiated & 5 \\
Moderately differentiated & 14 \\
Poorly differentiated & 11 \\
Adenocarcinoma & 8 \\
Large cell carcinoma & 6 \\
Small cell carcinoma & 6 \\
Lymph node metastasis & 30 \\
Positive & \\
Normal lung tissue & 20 \\
\hline
\end{tabular}

30 metastatic carcinoma, 20 normal lung tissues, and 20 other types of lung cancer (lung adenocarcinoma, large cell carcinoma, small cell carcinoma) was from AURAGENE. The detailed information of the tissues is provided in Table 1.

Serial sections $(4 \mu \mathrm{m})$ were cut from the tissue microarray, deparaffinized, rehydrated, and treated with an antigen retrieval solution ( $10 \mathrm{mmol} / \mathrm{L}$ sodium citrate buffer, $\mathrm{pH}$ 6.0). Endogenous peroxidase was blocked using 3\% hydrogen peroxide in methanol for $20 \mathrm{~min}$. Nonspecific sites were blocked for $20 \mathrm{~min}$ using $1 \%$ normal serum in PBS. Sections were incubated for $2 \mathrm{~h}$ with a dilution of $1: 200$ polyclonal rabbit anti-human S100A8/A9 or SCCA1 and then were incubated with $1: 1000$ dilution of biotinylated secondary antibody followed by avidin-biotin peroxidase complex (DAKO) according to the manufacturer's instructions. Finally, tissue sections were incubated with $3^{\prime}, 3^{\prime}$-diaminobenzidine (Sigma) until a brown color developed and counterstained with Harris' modified hematoxylin. In negative controls, primary antibodies were omitted.

2.7. Evaluation of Staining. Immunostaining was blindly evaluated by two observers in an effort to provide a consensus on staining patterns. Each case was rated according to a score that added a scale of intensity of staining to the area of staining. At least 10 high-power fields were chosen randomly, and $>1000$ cells were counted for each section. The positive intensity of staining was graded on the following scale: 0 , no staining; $1+$, pale yellow stained; $2+$, tan-yellow stained; and $3+$, brown stained. The negative intensity of staining was evaluated as follows: $0,<5 \%$ of tissue stained negative; $1+, 5 \%-25 \%$ of tissue stained negative; $2+$, between $25 \%$ and $50 \%$ stained negative; $3+, 50 \%-75 \%$ stained negative; and $4+,>75 \%$ stained negative. The minimum score when summed (positive stained + negative stained) was therefore 2 and the maximum, 7. A combined staining score (positive stained + negative stained) of $<2$ was considered to be negative staining (-); a score between 2 and 3 was considered to be weak staining $(+)$; between 3 and 6 was considered to be moderate staining $(++)$; and between 6 and 7 was considered to be strong staining $(+++)$.

2.8. Statistical Analysis. One-way analysis of variance (ANOVA) and LSD analysis (SPSS 12.0) were used in this study. All statistical tests were two-sided. Differences were considered statistically significant for $P$ values $<0.05$.

\section{Results}

3.1. Identification of Differentially Expressed Proteins in HLSC and NBE Using iTRAQ Labeling and 2D LC-MS/MS. A total of 96 differentially expressed proteins were identified by iTRAQ labeling and 2D LC-MS/MS, among which 49 upregulated and 47 downregulated proteins in HLSC (Table 2). MS/MS spectrum used for the identification and quantitation of CKB is shown in Figure 1.

Biological functions and subcellular location of the identified 96 proteins were searched in EMBL-EBI and EXPASY database. The most common differential expression proteins were located in the cytoplasm, followed by nuclear proteins, secreted proteins, and mitochondrial proteins. The locations of the proteins were concomitant with their functions, which were structural proteins, metabolic enzymes, signal transduction proteins, cell adhesion, and proliferation-related proteins (Figure 2).

\subsection{Validation of Differentially Expressed Proteins Indentified by Proteomics. Five proteins (HSPB1, S100A8/A9, CKB, and SCCA1) identified by MS analysis were chosen for verifica- tion. Western blotting was performed to detect the expres- sional levels of the four proteins in 10 cases of LCM-pu- rified NBE and HLSC. As shown in Figure 3, HSPB1 and S100A8/A9 were upregulated, whereas CKB and SCCA1 were downregulated in the HLSC versus NBE $(P<0.05)$, which is consistent with the findings in MS analysis.}

3.3. Detection of the Expression of the Differential Proteins by TMA and Immunohistochemistry. The expressions of SCCA1, S100A8/A9 in 30 squamous cell carcinoma, 30 metastatic carcinoma, and 20 nonsquamous cell carcinoma (8 adenocarcinoma, 6 large cell carcinoma, 6 small cell carcinoma) were detected by TMA and immunohistochemisry. As shown in Figure 4 and Table 3, the expressions of SCCA1 in lung squamous cell carcinoma, other types of lung carcinoma, and metastatic carcinoma were lower than those in normal lung tissue $(P<0.05)$. As shown in Figure 5 and Table 4, S100A8/A9 was expressed in all types of lung cancer and normal tissues. Yet, the expression of S100A8 in lung squamous cell carcinoma was stronger than that in normal tissues and other types of lung cancer tissues $(P<0.05)$. As shown in Figure 6 and Table 5, the expression of S100A9 in cancer tissues including lung squamous cell carcinoma, 
TABLE 2: Differential expressed proteins in LCM-purified HLSC and NHBE identified by mass spectrometry.

\begin{tabular}{|c|c|c|c|c|c|c|}
\hline No. of proteins & Coverage (\%) & UniprotKB & $\mathrm{AC}$ & Name & Peptides & $115: 113$ \\
\hline 1 & 62.34 & IPI00554648.3 & P05787 & KRT8 & 60 & 0.4098 \\
\hline 2 & 60.05 & IPI00479145.2 & P08727 & KRT19 & 51 & 0.6193 \\
\hline 3 & 56.53 & IPI00745872.2 & P02768 & ALB & 40 & 0.5735 \\
\hline 4 & 59.8 & IPI00009867.3 & P13647 & KRT5 & 68 & 0.7839 \\
\hline 5 & 54.17 & IPI00019502.3 & P35579 & MYH9 & 32 & 1.6587 \\
\hline 6 & 39.41 & IPI00007752.1 & P68371 & TUBB2C & 37 & 0.1989 \\
\hline 7 & 35.87 & IPI00784154.1 & P10809 & HSPD1 & 30 & 1.5497 \\
\hline 8 & 34.28 & IPI00479186.5 & P14618 & PKM2 & 21 & 1.5827 \\
\hline 9 & 34.2 & IPI00844215.1 & Q13813 & SPTAN1 & 17 & 0.5947 \\
\hline 10 & 42.7 & IPI00450768.7 & Q04695 & KRT17 & 25 & 0.7824 \\
\hline 11 & 30.05 & IPI00219018.7 & P04406 & GAPDH & 22 & 1.5761 \\
\hline 12 & 28.96 & IPI00845339.1 & P08107 & HSPA1A/1B & 15 & 0.5216 \\
\hline 13 & 27.82 & IPI00022204.2 & P29508 & SERPINB3 & 16 & 0.3215 \\
\hline 14 & 31.05 & IPI00554788.5 & P05783 & KRT18 & 32 & 0.5866 \\
\hline 15 & 50.34 & IPI00300725.7 & P02538 & KRT6A & 59 & 1.6359 \\
\hline 16 & 24.25 & IPI00553177.1 & P01009 & SERPINA1 & 13 & 0.651 \\
\hline 17 & 23.08 & IPI00654755.3 & P68871 & HBB & 19 & 1.4246 \\
\hline 18 & 22.65 & IPI00455383.4 & Q00610 & CLTC & 12 & 0.6788 \\
\hline 19 & 23.9 & IPI00003362.2 & P11021 & HSPA5 & 13 & 1.9385 \\
\hline 20 & 20.99 & IPI00025252.1 & P30101 & PDIA3 & 14 & 1.477 \\
\hline 21 & 19.32 & IPI00218914.5 & P00352 & ALDH1A1 & 11 & 0.3403 \\
\hline 22 & 35.01 & IPI00217963.3 & P08779 & KRT16 & 19 & 1.7771 \\
\hline 23 & 18.49 & IPI00872684.1 & P15311 & EZR & 9 & 0.3327 \\
\hline 24 & 16.7 & IPI00013808.1 & O43707 & 4ACTN4 & 14 & 0.4979 \\
\hline 25 & 33.95 & IPI00290077.1 & P19012 & KRT15 & 20 & 0.6399 \\
\hline 26 & 16 & IPI00219757.13 & P09211 & GSTP1 & 13 & 0.5584 \\
\hline 27 & 15.06 & IPI00000105.4 & Q14764 & MVP & 7 & 0.516 \\
\hline 28 & 14.96 & IPI00645078.1 & P22314 & UBA1 & 8 & 1.345 \\
\hline 29 & 14.66 & IPI00788802.1 & P29401 & TKT & 8 & 1.4856 \\
\hline 30 & 13.96 & IPI00020599.1 & P27797 & CALR & 7 & 2.1548 \\
\hline 31 & 13.57 & IPI00169383.3 & P00558 & PGK1 & 8 & 0.6459 \\
\hline 32 & 13.23 & IPI00887678.1 & & LOC654188 & 8 & 2.2579 \\
\hline 33 & 12.44 & IPI00640741.1 & Q06830 & PRDX1 & 6 & 6.5599 \\
\hline 34 & 12.12 & IPI00604620.3 & P19338 & NCL & 7 & 1.5576 \\
\hline 35 & 12.1 & IPI00893881.1 & Q53G64 & AGR2 & 14 & 0.4388 \\
\hline 36 & 11.27 & IPI00853068.1 & Q86YQ1 & HBA & 11 & 1.372 \\
\hline 37 & 11.23 & IPI00816252.1 & & $\mathrm{H} 2 \mathrm{BFS}$ & 18 & 1.4498 \\
\hline 38 & 11.14 & IPI00657682.2 & P08263 & GSTA1 & 6 & 0.2536 \\
\hline 39 & 11.01 & IPI00643384.2 & A6NLG9 & BGN & 5 & 0.2803 \\
\hline 40 & 23.25 & IPI00550661.2 & P13646 & KRT13 & 20 & 2.3013 \\
\hline 41 & 38.63 & IPI00384444.5 & P02533 & KRT14 & 19 & 1.448 \\
\hline 42 & 10.4 & IPI00027497.5 & P06744 & GPI & 4 & 2.4216 \\
\hline 43 & 9.95 & IPI00027462.1 & P06702 & S100A9 & 7 & 3.1824 \\
\hline 44 & 9.85 & IPI00215948.4 & P35221 & CTNNA1 & 5 & 0.6596 \\
\hline 45 & 9.76 & IPI00453473.6 & P62805 & HIST1H4I & 5 & 15.7322 \\
\hline 46 & 9.42 & IPI00794543.1 & A8K1M2-cDNA & FLJ75174 & 4 & 0.3772 \\
\hline 47 & 9.08 & IPI00549248.4 & P06748 & NPM1 & 9 & 2.033 \\
\hline 48 & 8.97 & IPI00221226.7 & P08133 & ANXA6 & 4 & 0.6198 \\
\hline 49 & 8.63 & IPI00032140.4 & P50454 & SERPINH1 & 4 & 2.9965 \\
\hline
\end{tabular}


TABLE 2: Continued.

\begin{tabular}{|c|c|c|c|c|c|c|}
\hline No. of proteins & Coverage (\%) & UniprotKB & $\mathrm{AC}$ & Name & Peptides & $115: 113$ \\
\hline 50 & 8.55 & IPI00025512.2 & P04792 & HSPB1 & 20 & 3.9981 \\
\hline 51 & 8.14 & IPI00798430.1 & Q53H26 & $\mathrm{TF}$ & 4 & 0.6764 \\
\hline 52 & 35.45 & IPI00011654.2 & P07437 & TUBB & 28 & 1.5243 \\
\hline 53 & 8 & IPI00022977.1 & P12277 & СКВ & 4 & 0.41 \\
\hline 54 & 7.84 & IPI00307162.2 & P18206 & VCL & 5 & 2.4223 \\
\hline 55 & 7.22 & IPI00295400.1 & P23381 & WARS & 3 & 1.4314 \\
\hline 56 & 6.92 & IPI00792011.1 & Q8NF12 & CAPS & 5 & 0.3241 \\
\hline 57 & 6.36 & IPI00013415.1 & P62081 & RPS7 & 3 & 3.2407 \\
\hline 58 & 6.27 & IPI00025465.1 & P20774 & OGN & 4 & 0.1986 \\
\hline 59 & 6.24 & IPI00853455.1 & С9JIH9 & CTSD & 4 & 0.639 \\
\hline 60 & 6.19 & IPI00152295.1 & Q8TC71 & SPATA18 & 3 & 0.4421 \\
\hline 61 & 9.34 & IPI00829767.1 & P01859 & IGHG2 & 4 & 0.6251 \\
\hline 62 & 6 & IPI00789551.1 & A8MXP9 & MATR3 & 5 & 2.0326 \\
\hline 63 & 6 & IPI00871851.1 & Q15019 & SEPT2 & 4 & 1.3502 \\
\hline 64 & 6 & IPI00291006.1 & P40926 & $\mathrm{MDH} 2$ & 3 & 1.924 \\
\hline 65 & 6 & IPI00795633.1 & Q8IWL5 & CLU & 3 & 0.3392 \\
\hline 66 & 5.95 & IPI00423462.5 & Q6N092 & IGHA1 & 3 & 0.7002 \\
\hline 67 & 8.33 & IPI00007047.1 & P05109 & S100A8 & 5 & 2.1281 \\
\hline 68 & 5.73 & IPI00654709.1 & Q6PKA6 & ALDH3A1 & 3 & 0.431 \\
\hline 69 & 4.72 & IPI00294834.6 & Q12797 & $\mathrm{ASPH}$ & 2 & 2.3432 \\
\hline 70 & 6.6 & IPI00027350.3 & P32119 & PRDX2 & 3 & 1.7333 \\
\hline 71 & 4.45 & IPI00025086.3 & P20674 & COX5A & 2 & 1.4661 \\
\hline 72 & 4.4 & IPI00009032.1 & P05455 & SSB & 2 & 0.6693 \\
\hline 73 & 4.4 & IPI00060715.1 & Q96CX2 & KCTD12 & 2 & 0.7126 \\
\hline 74 & 4.31 & IPI00646059.1 & Q5VXV2 & SET & 2 & 2.3791 \\
\hline 75 & 4.13 & IPI00216308.5 & P21796 & VDAC1 & 2 & 0.4488 \\
\hline 76 & 4.08 & IPI00032179.2 & P01008 & SERPINC1 & 2 & 0.6734 \\
\hline 77 & 4.01 & IPI00025796.3 & O75489 & NDUFS3 & 2 & 0.6022 \\
\hline 78 & 4 & IPI00020042.2 & P43686 & PSMC4 & 2 & 0.603 \\
\hline 79 & 4 & IPI00011126.6 & P62191 & PSMC1 & 2 & 0.6418 \\
\hline 80 & 3.71 & IPI00883950.1 & Q8TB01 & CKAP4 & 2 & 2.3486 \\
\hline 81 & 2.95 & IPI00420014.2 & O75643 & ASCC3L1 & 1 & 1.6656 \\
\hline 82 & 2.73 & IPI00003944.1 & P11182 & DBT & 1 & 0.5156 \\
\hline 83 & 2.58 & IPI00479786.4 & Q92945 & KHSRP & 1 & 1.9958 \\
\hline 84 & 2.38 & IPI00419237.3 & P28838 & LAP3 & 1 & 1.7329 \\
\hline 85 & 2.34 & IPI00024933.3 & P30050 & RPL12 & 1 & 1.7853 \\
\hline 86 & 2.19 & IPI00219221.3 & P47929 & LGALS7 & 1 & 0.7374 \\
\hline 87 & 2.02 & IPI00444204.1 & Q6ZS74 & ALB & 1 & 2.0254 \\
\hline 88 & 2.02 & IPI00847322.1 & Q4ZJI1 & SOD2 & 1 & 0.6501 \\
\hline 89 & 2.01 & IPI00745729.2 & A6PVW9 & SELENBP1 & 1 & 0.5016 \\
\hline 90 & 2.01 & IPI00375746.4 & Q6ZN66 & GBP6 & 1 & 4.68 \\
\hline 91 & 2 & IPI00413654.3 & Q13243 & SFRS5 & 1 & 4.0553 \\
\hline 92 & 2 & IPI00010133.3 & P31146 & CORO1A & 1 & 1.5283 \\
\hline 93 & 2 & IPI00221222.7 & P53999 & SUB1 & 1 & 7.5809 \\
\hline 94 & 2 & IPI00024976.5 & Q9NS69 & TOMM22 & 1 & 2.5511 \\
\hline 95 & 2 & IPI00888660.1 & & SDHA & 1 & 2.0706 \\
\hline 96 & 2 & IPI00013895.1 & P31949 & S100A11 & 2 & 0.6028 \\
\hline
\end{tabular}

Differentially labeled proteins are identified by QSTAR. The \% coverage of analyzed peptides and Swiss-Prot accession number were shown for each protein. Proteins displaying an average fold-difference of $\geq 1.2$-fold up- $(+)$ or $\leq 0.8$-fold down- $(-)$ regulation between pairs of conditions where $P<0.05$ are shown (115: the group of HLSC; 113: the group of NHBE). 


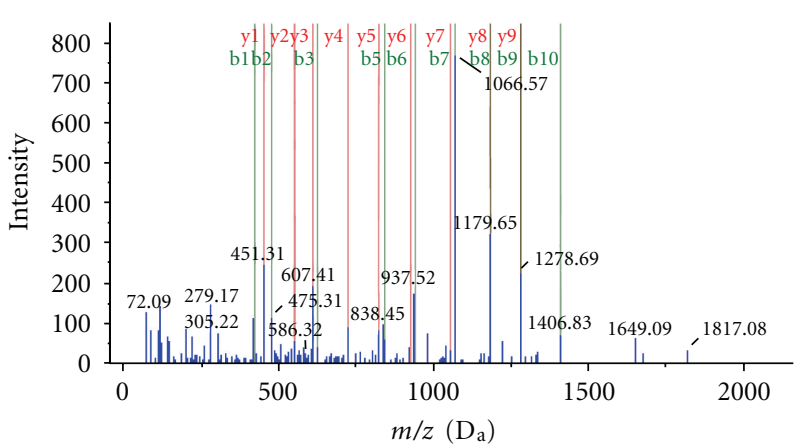

(a)

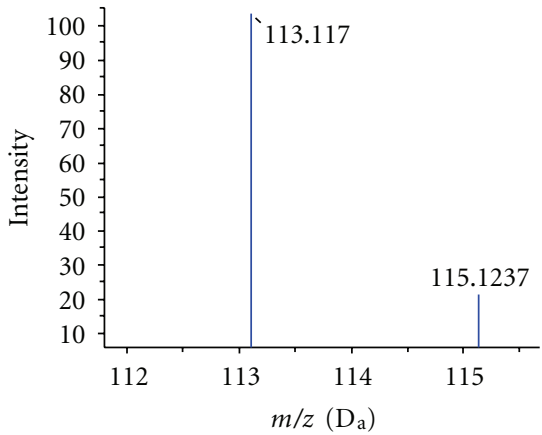

(b)

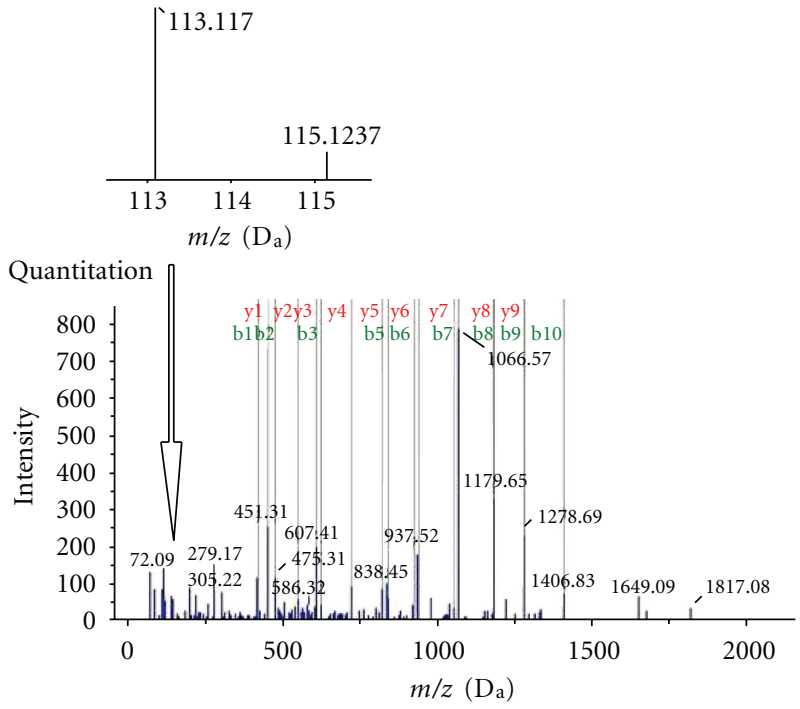

(c)

FIGURE 1: The fragment ion spectra of peptide sequence tag (PST) from CKB protein, highlighting the relative abundances of overexpression in NHBE. The ion assignments are as follows: 113: NHBE; and 115: HLSC.

metastatic carcinoma, and other types of lung cancer was stronger than in normal tissues $(P<0.05)$.

\section{Discussion}

Recently, numerous successful explorations about carcinogenic molecular mechanisms of HLSC on gene and transcription were reported. Compared with genome and transcriptome, which is relatively static and will be transcribed into a variety of functionally distinct proteins, proteome may provide a more realistic picture of function aberrations in cancer cells. Proteomics has become the frontier era of the postgenomic; the new methods and achievements are emerging in large number. Traditional 2-DE technique has been used widely for comparative proteomics with a significant achievement, but also there is disadvantagedness. iTRAQ quantitative proteomics can overcome that deficiencies (such as identified membrane proteins) and increase the number and types of differential expression proteins. In contrast to 2-DE, iTRAQ technology has a better repeatability and quantification.

In the study, LCM was used to purify the target cells from HLSC tissues and matched NHBE, respectively. A stable isotope-labeled strategy using iTRAQ, followed by 2D-LC/QSTAR mass spectrometry, was performed to separate and identify the differential expression proteins. A total of 96 differential expression proteins in the LCM-purified HLSC and NHBE were identified.

Among the differential expression proteins, HSPB1 (HSP27) is heat shock protein family member, which has important biological functions, a chaperone protein involved in regulation of cell proliferation, differentiation, apoptosis and signal transduction, and so forth. Induced epithelialmesenchymal transition (EMT) in human lung cancer cells (adenocarcinoma cells), HSPB1, was high-regulated and involved in the regulation of cell migration, adhesion and invasion [8]. In the colon, prostate, and breast cancer, HSPB1 expression was associated with tumor occurrence and metastasis. HSPB1 was high-regulated, suggesting the poor prognosis and resistance to drugs [9-12]. Guo et al. found that the functional HSPB1 promoter $-1271 \mathrm{G}>\mathrm{C}$ variant may affect lung cancer susceptibility and survival by modulating endogenous HSPB1 synthesis levels [13]. The research showed HSPB1 protein and its phosphorylation increased in parallel with enhanced metastatic potentials of hepatocellular carcinoma (HCC) cells; HSPB1 knockdown significantly 


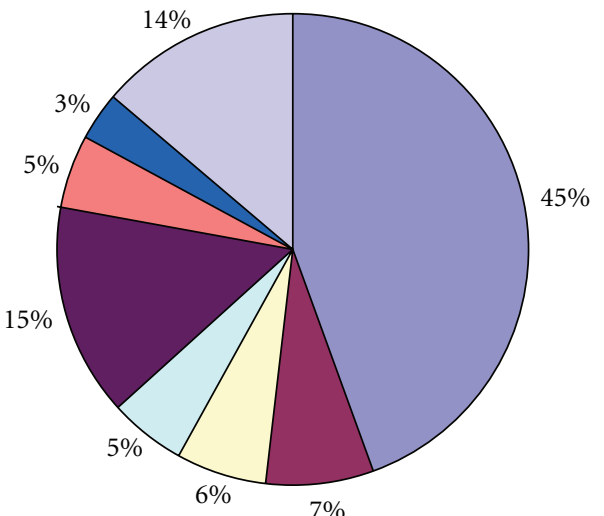

Cytoplasm

$\square$ Secreted

$\square$ Mitochondrion

$\square$ Endoplasmic reticulum lumen

(a)

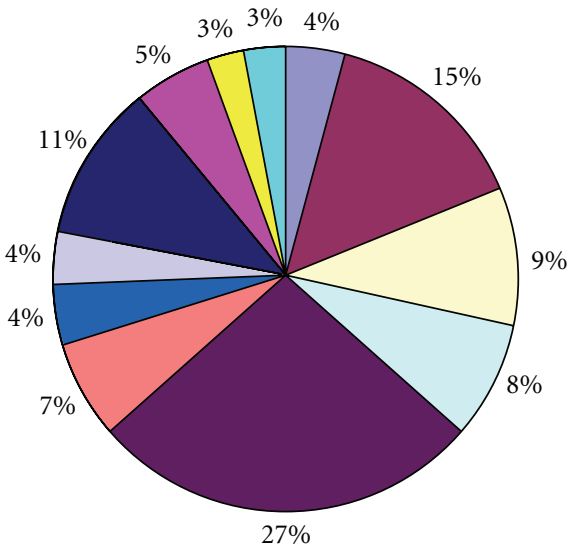

Protein binding

Cytoskeleton

$\square$ Motility

$\square$ Transport

Metabolic enzymes

Apoptosis

$\square$ Immune response

Differentiation $\square$ Signal transducer

$\square$ Transcription and translation

Channel

Ca binding

FIGURE 2: Biological functions and subcellular location of the identified 96 proteins. (a) A pie chart representing the distribution of the identified 96 proteins according to their cellular locations; (b) A pie chart representing the distribution of the identified 96 proteins according to their biological function.

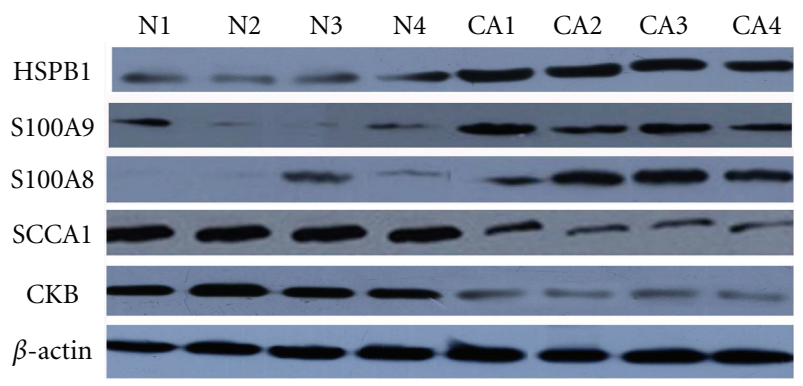

(a)

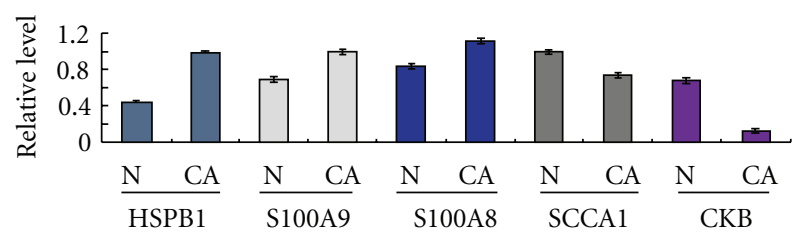

(b)

FIGURE 3: Representative results of Western blotting analysis of HSPB1, CKB, S100A8/A9, and SCCA1 in HLSC (CA) and NHBE (N). $\beta$-actin was used as a loading control.

TABLE 3: SCCA1 expression in various tissues by IHC.

\begin{tabular}{|c|c|c|c|c|c|}
\hline Classification & Number & - & + & ++-+++ & $P$ value \\
\hline Squamous cell carcinomas & 30 & 21 & 5 & 4 & $0.038^{\mathrm{a}}$ \\
\hline High differentiated & 3 & 3 & 0 & 0 & $0.406^{\mathrm{b}}$ \\
\hline Moderately differentiated & 11 & 9 & 2 & 0 & \\
\hline Poorly differentiated & 10 & 6 & 2 & 2 & \\
\hline Normal lung tissue & 20 & 9 & 10 & 1 & \\
\hline Metastatic carcinoma & 29 & 16 & 5 & 8 & $0.029^{c}$ \\
\hline Other types & 20 & 12 & 6 & 2 & $0.001^{\mathrm{d}}$ \\
\hline
\end{tabular}

${ }^{\mathrm{a}} P<0.05$ by LSD, squamous cell carcinomas versus normal lung tissue. ${ }^{\mathrm{b}} P>0.05$ by ANOVA, high differentiated versus moderately versus poorly. ${ }^{\mathrm{c}} P<0.05$ by LSD, metastatic carcinoma versus normal lung tissue. ${ }^{\mathrm{d}} P<0.05$ by LSD, other types versus normal lung tissue. 


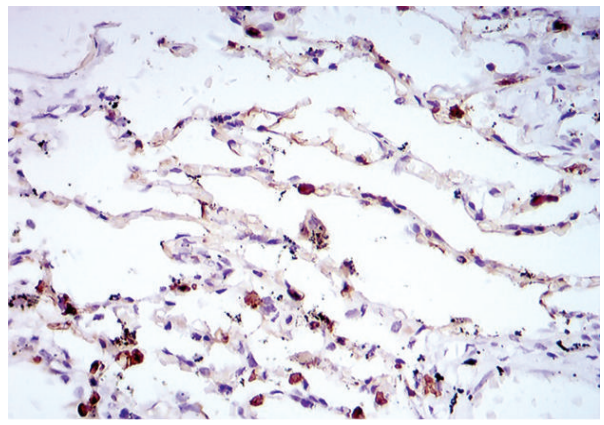

(a)

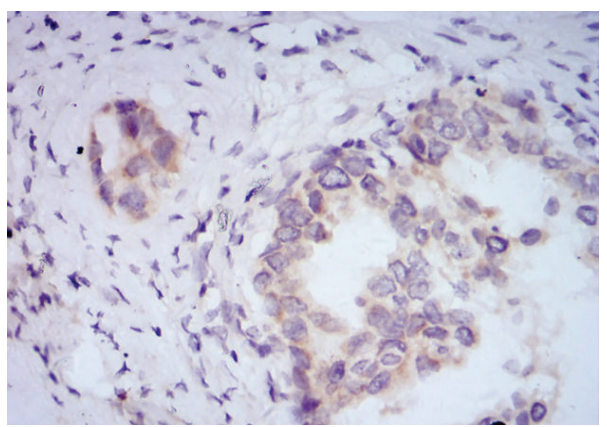

(c)

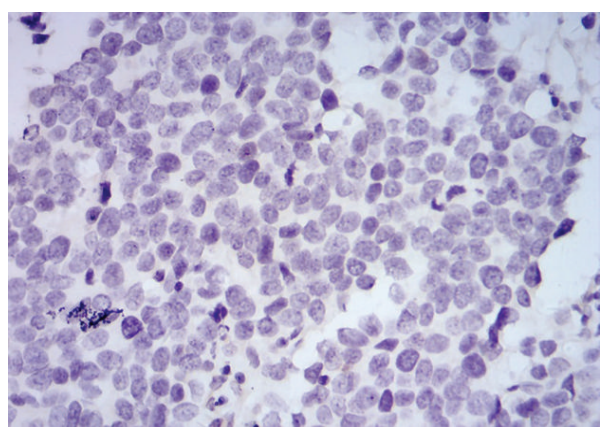

(e)

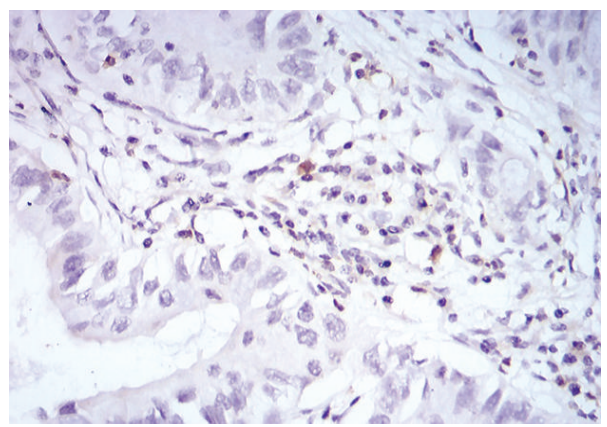

(b)

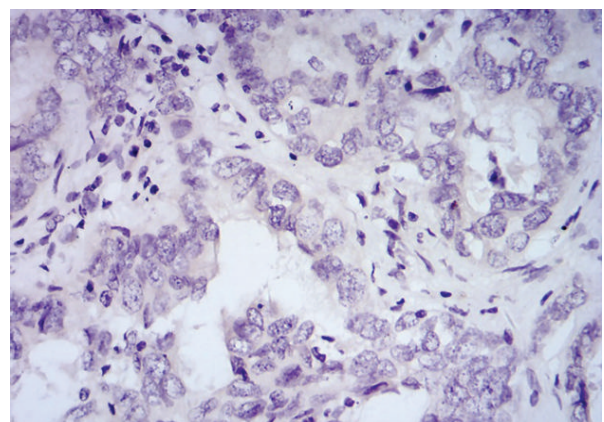

(d)

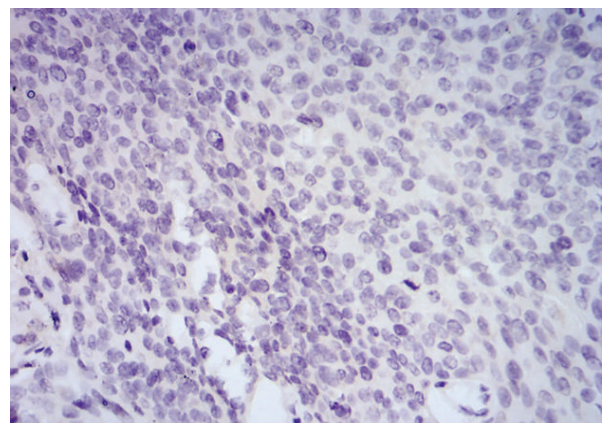

(f)

FIGURE 4: Immunohistochemistry staining in tissue chip of SCCA1 protein expression in lung cancer tissue and normal tissues ((a) normal lung tissue, (b) lung squamous cell carcinomas, (c) metastatic carcinoma, (d) adenocarcinoma, (e) small cell carcinoma, (f) large cell carcinoma tissues).

TABLE 4: S100A8 expression in various tissues by IHC.

\begin{tabular}{|c|c|c|c|c|c|}
\hline Classification & Number & - & + & ++-+++ & $P$ value \\
\hline Squamous cell carcinomas & 30 & 1 & 5 & 24 & $0.000^{\mathrm{a}}$ \\
\hline High differentiated & 3 & 0 & 0 & 3 & $0.705^{\mathrm{b}}$ \\
\hline Moderately differentiated & 11 & 2 & 7 & 2 & \\
\hline Poorly differentiated & 10 & 6 & 2 & 2 & \\
\hline Normal lung tissue & 20 & 1 & 11 & 8 & \\
\hline Metastatic carcinoma & 29 & 0 & 11 & 18 & $0.007^{\mathrm{c}}$ \\
\hline Other types & 20 & 3 & 12 & 5 & $0.000^{\mathrm{d}}$ \\
\hline
\end{tabular}

${ }^{\mathrm{a}} P<0.05$ by LSD, squamous cell carcinomas versus normal lung tissue. ${ }^{\mathrm{b}} P>0.05$ by ANOVA, high differentiated versus moderately versus poorly. ${ }^{\mathrm{c}} P<0.05$ by LSD, metastatic carcinoma versus normal lung tissue. ${ }^{\mathrm{d}} P<0.05$ by LSD, other types versus normal lung tissue. 


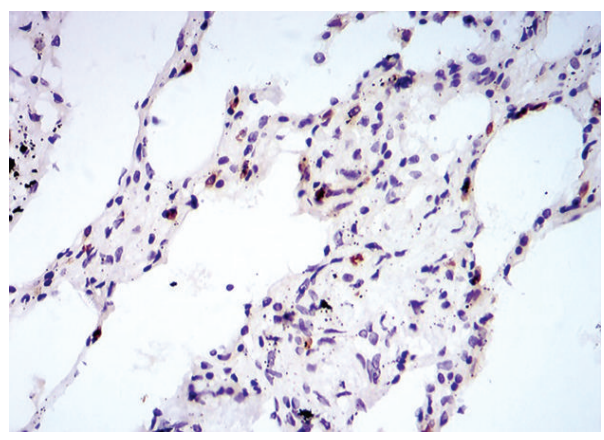

(a)

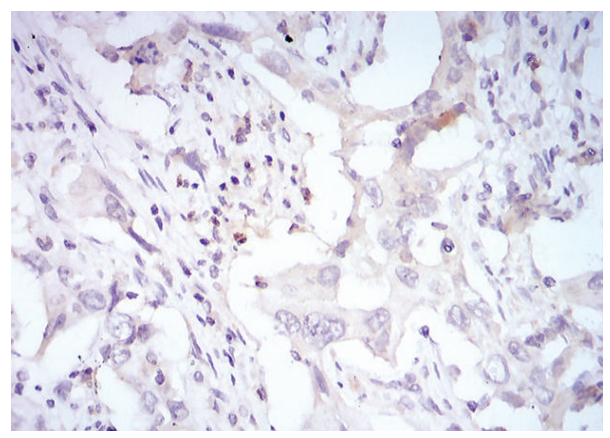

(c)

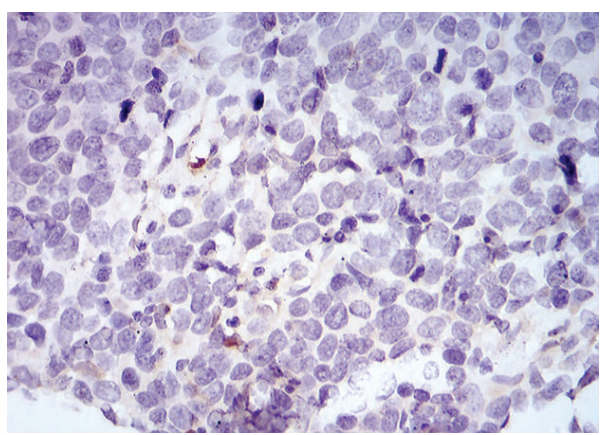

(e)

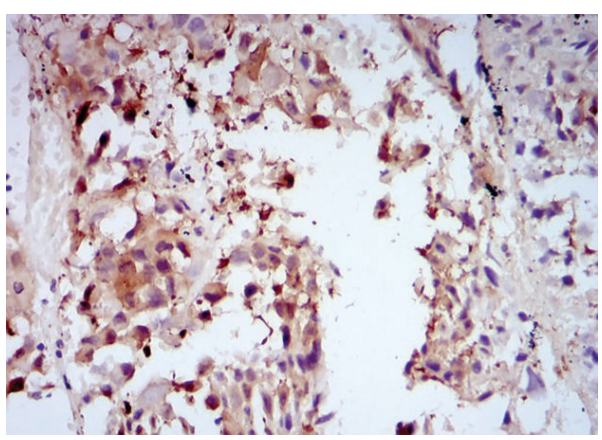

(b)

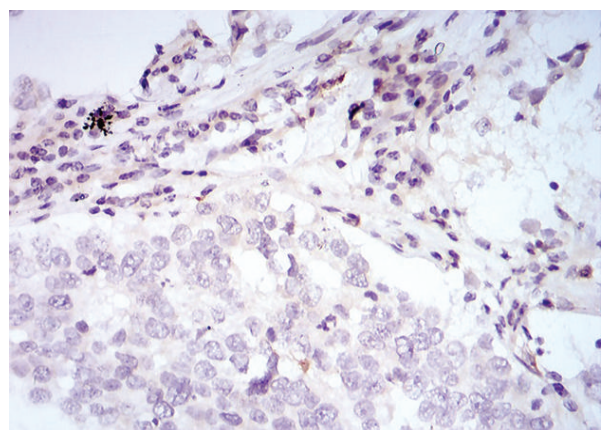

(d)

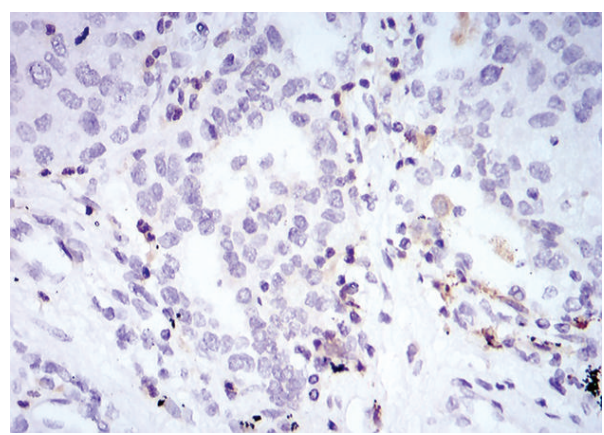

(f)

FIGURE 5: Immunohistochemistry staining in tissue chip of S100A8 protein expression in lung cancer tissue and normal tissues ((a) normal lung tissue, (b) lung squamous cell carcinomas, (c) metastatic carcinoma, (d) adenocarcinoma, (e) small cell carcinoma, (f) large cell carcinoma tissues).

TABLE 5: S100A9 expression in various tissues by IHC.

\begin{tabular}{|c|c|c|c|c|c|}
\hline Classification & Number & - & + & ++-+++ & Pvalue \\
\hline Squamous cell carcinomas & 30 & 0 & 2 & 28 & $0.01^{\mathrm{a}}$ \\
\hline High differentiated & 3 & 0 & 3 & 0 & $0.705^{\mathrm{b}}$ \\
\hline Moderately differentiated & 11 & 9 & 2 & 0 & \\
\hline Poorly differentiated & 10 & 8 & 2 & 0 & \\
\hline Normal lung tissue & 20 & 0 & 10 & 10 & \\
\hline Metastatic carcinoma & 29 & 0 & 4 & 25 & $0.000^{\mathrm{c}}$ \\
\hline Other types & 20 & 0 & 2 & 18 & $0.000^{\mathrm{d}}$ \\
\hline
\end{tabular}

${ }^{\text {a } P}<0.05$ by LSD, squamous cell carcinomas versus normal lung tissue. ${ }^{\mathrm{b}} P>0.05$ by ANOVA, high differentiated versus moderately versus poorly. ${ }^{\mathrm{c}} P<$ 0.05 by LSD, metastatic carcinoma versus normal lung tissue. ${ }^{\mathrm{d}} P<0.05$ by LSD, other types versus normal lung tissue. 


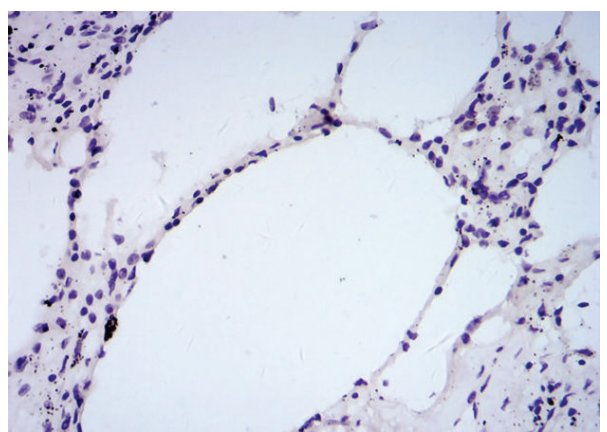

(a)

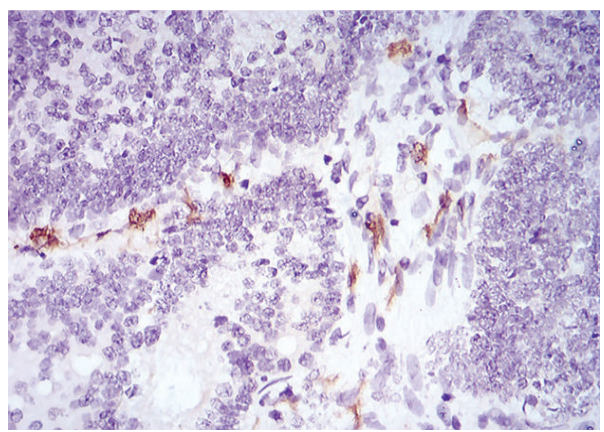

(c)

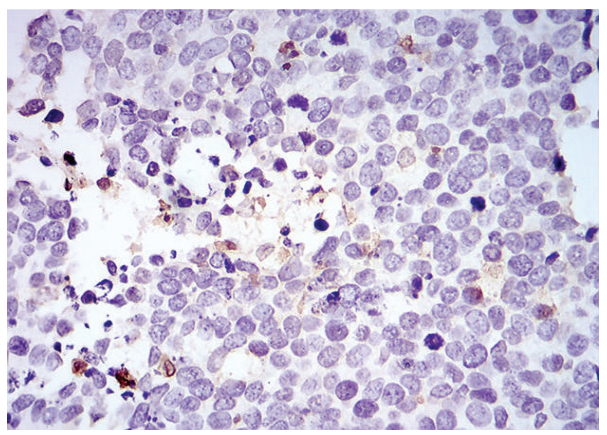

(e)

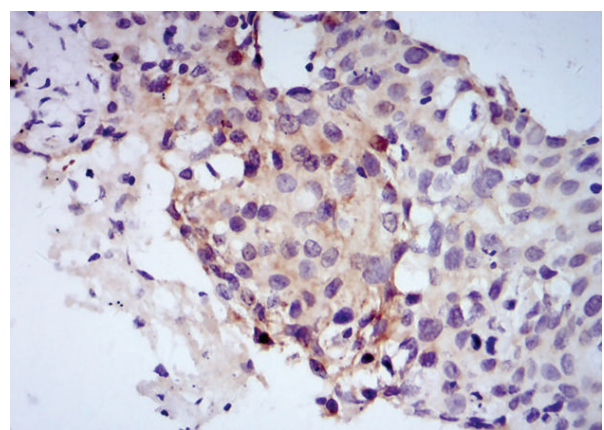

(b)

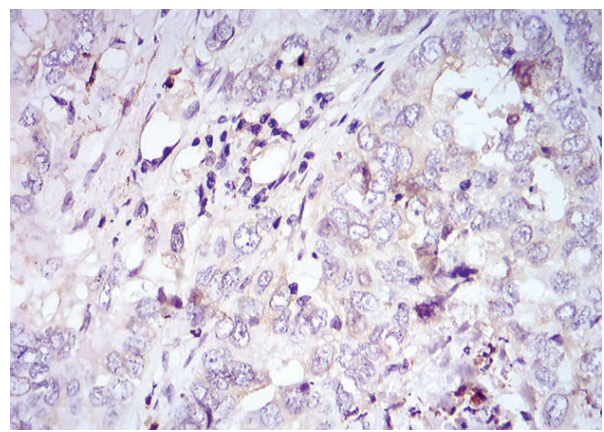

(d)

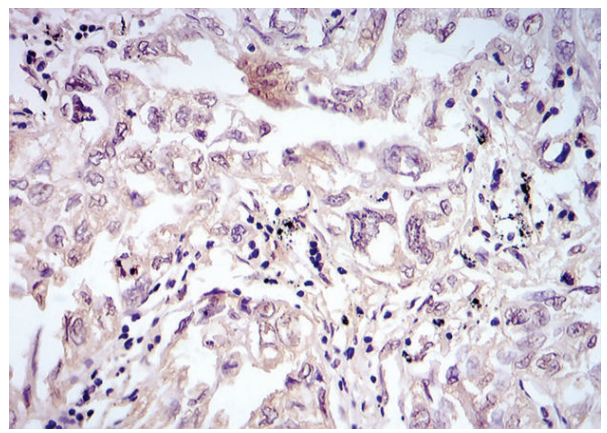

(f)

FIGURE 6: Immunohistochemistry staining in tissue chip of S100A9 protein expression in lung cancer tissue and normal tissues ((a) normal lung tissue, (b) lung squamous cell carcinomas, (c) metastatic carcinoma, (d) adenocarcinoma, (e) small cell carcinoma, (f) large cell carcinoma tissues).

suppressed cells migration and invasion and induced cell apoptosis [14]. Ye et al. showed that upregulated HSPB1 expression was potentially involved in human oral squamous cell carcinoma growth and metastasis [15]. In our study, HSPB1 was upregulated in HLSC compared with NHBE, confirmed by Western blot analysis. It was suggested that HSPB1 might play a certain role in carcinogenic of HLSC.

CKB (creatinekinase B) is a member of the creatine kinase family, that exists widely in as skeletal muscle, myocardial, nerve tissue, and mitochondria. CKB participated in energy signaling pathways and catalyzed phosphate group reversibly from creatine phosphate to ADP to generate ATP and creatine. $\mathrm{CKB}$ expressed in the organization demanded high energy, as a nuclear "energy supplier". CKB was downregulated protein in human prostate cancer cells associated with progression [16]. Reduced expression has been reported in colon, and renal cancer compared with matched adjacent normal tissues $[17,18]$. Our finding of reduced levels of $\mathrm{CKB}$ in human lung squamous carcinoma suggests a novel association for CKB with HLSC which needs to be investigated further.

SCCA1 (Squamous cell carcinoma antigen 1) also named SERPINB3 (serine protease inhibitor3) belonged to serine protease inhibitor family, that was physiologically found in normal squamous epithelium but overexpressed in squamous cell carcinoma (lung, cervical, esophagus, etc.). The biological role of this serpin in carcinogenesis has not been defined. On the one hand, SCCA1 can decrease NK tumour invasion [19] and inhibit apoptosis by inhibiting P38 phosphorylation and release of $C$ cytochromes $[20,21]$. Elevated levels of SCCA1 have been reported in liver, esophagus, mammary carcinoma, and so forth, associated with malignant cancer, prognosis, and recurrence [22]. In a previous study, it was reported that SCCA1 expression levels 
were associated with tumor progression. Increasing number of reports suggests that SCCA has been implicated as a tumor marker for squamous [23]. Interestingly, our finding is that SCCA1 levels were downregulated in human lung squamous carcinoma compared with corresponding normal tissue. Our laboratory reported that SCCA1 levels were downregulated in nasopharyngeal carcinoma by promoter methylation [24]. Whether lung squamous carcinoma exists in promoter methylation, further analysis of the expression of SCCA1 in preneoplastic lesions for squamous cell carcinoma of the lung is needed.

Heterodimer S100A8/A9 is the member of calciumbinding protein S100 protein family, the inflammation factor, and inhibition of casein kinase I, II activity. Physically, S100A8/A9 is expressed as the early stages of cell differentiation in bone marrow and granulocytes and monocytes in circulation. Some inflammatory diseases, such as rheumatoid rheumatoid arthritis, inflammatory bowel disease, chronic pneumonia, their epithelial cells, and the cells of inflammatory exudate in early stage of inflammatory diseases express S100A8/A9. Elevated levels of S100A8/A9 have been reported in lung, stomach, breast, pancreatic, prostate cancer, and so forth. In addition, S100A9 has correlation with the poor differentiation of breast, lung, and thyroid cancer [7, 25-27]. Iikawa reveals a novel role for myeloid-derived S100A8/A9 in activating MAPK and NF- $\kappa$ B signaling pathways associated with colon tumorigenesis and in promoting tumor growth and metastasis [28]. Our findings are consistent with the reported that S100A8/A9 is upregulated in human lung squamous carcinoma compared with corresponding normal tissue. Although many possible functions have been proposed for S100A8/A9, its biological role still remains to be defined.

\section{Conclusions}

In conclusion, our data suggest that the several differential expression proteins may play a key role in human lung squamous carcinoma. Known to that during the development of human lung squamous cell carcinoma, bronchial epithelial cells exhibit a progressive series of morphologically distinct changes: hyperplasia, squamous metaplasia, dysplasia, carcinoma in situ, and finally invasive squamous cell carcinoma. We seek to identify differential expression proteins that can be used to monitor these premalignant changes under the assumption that these morphologic changes are accompanied by abnormal expression proteins. Thus, additional research using a larger number of tumor specimens is needed to confirm our findings more assuredly and we will make greater efforts to elucidate the precise molecular mechanisms of how the protein acts on the carcinogenesis in future works.

\section{Author's Contribution}

X. Yan, C. Lan-Qin, and J. Long-Yu contributed equally to this work.

\section{Acknowledgments}

This work is supported by the National Natural Science Foundation of China (no. 30972970), Program for New Century Excellent Talents in University (2007-0861), Nature Scientific Foundation of Hunan Province (08JJ6010), and Scientific Research Foundation of Department of Public Health of Hunan Province (B2007-068; B2010-037); Scientific Research Fund of Department of Education of Hunan Province (09C837), China.

\section{References}

[1] A. D. Lopez, "Counting the dead in China measuring tobacco inpact in the developing world," BMJ, vol. 317, no. 170, pp. 1399-1400, 1998.

[2] R. F. Bonner, M. Emmert-Buck, K. Cole et al., "Laser capture microdissection: molecular analysis of tissue," Science, vol. 278, no. 5342, pp. 1481-1491, 1997.

[3] A. R. Shekouh, C. C. Thompson, W. Prime et al., "Application of laser capture microdissection combined with twodimensional electrophoresis for the discovery of differentially regulated proteins in pancreatic ductal adenocarcinoma," Proteomics, vol. 3, no. 10, pp. 1988-2001, 2003.

[4] C. Li, Y. Hong, Y. X. Tan et al., "Accurate qualitative and quantitative proteomic analysis of clinical hepatocellular carcinoma using laser capture microdissection coupled with isotope-coded affinity tag and two-dimensional liquid chromatography mass spectrometry," Molecular and Cellular Proteomics, vol. 3, no. 4, pp. 399-409, 2004.

[5] H. Neubauer, S. E. Clare, R. Kurek et al., "Breast cancer proteomics by laser capture microdissection, sample pooling, 54cm IPG IEF, and differential iodine radioisotope detection," Electrophoresis, vol. 27, no. 9, pp. 1840-1852, 2006.

[6] V. Patel, B. L. Hood, A. A. Molinolo et al., "Proteomic analysis of laser-captured paraffin-embedded tissues: a molecular portrait of head and neck cancer progression," Clinical Cancer Research, vol. 14, no. 4, pp. 1002-1014, 2008.

[7] K. Arai, T. Teratani, R. Kuruto-Niwa, T. Yamada, and R. Nozawa, "S100A9 expression in invasive ductal carcinoma of the breast: S100A9 expression in adenocarcinoma is closely associated with poor tumour differentiation," European Journal of Cancer, vol. 40, no. 8, pp. 1179-1187, 2004.

[8] V. G. Keshamouni, G. Michailidis, C. S. Grasso et al., "Differential protein expression profiling by iTRAQ-2DLC-MS/MS of lung cancer cells undergoing epithelial-mesenchymal transition reveals a migratory/invasive phenotype," Journal of Proteome Research, vol. 5, no. 5, pp. 1143-1154, 2006.

[9] C. Garrido, A. Fromentin, B. Bonnotte et al., "Heat shock protein 27 enhances the tumorigenicity of immunogenic rat colon carcinoma cell clones," Cancer Research, vol. 58, no. 23, pp. 5495-5499, 1998.

[10] C. Garrido, P. Mehlen, A. Fromentin et al., "Inconstant association between 27-kDa heat-shock protein (Hsp27) content and doxorubicin resistance in human colon cancer cells: the doxorubicin-protecting effect of Hsp27," European Journal of Biochemistry, vol. 237, no. 3, pp. 653-659, 1996.

[11] D. R. Ciocca and L. M. Vargas-Roig, "Hsp27 as a prognostic and predictive factor in cancer," Progress in Molecular and Subcellular Biology, vol. 28, pp. 205-218, 2002.

[12] P. Rocchi, A. So, S. Kojima et al., "Heat shock protein 27 increases after androgen ablation and plays a cytoprotective 
role in hormone-refractory prostate cancer," Cancer Research, vol. 64, no. 18, pp. 6595-6602, 2004.

[13] H. Guo, Y. Bai, P. Xu et al., "Functional promoter -1271G >C variant of HSPB1 predicts lung cancer risk and survival," Journal of Clinical Oncology, vol. 28, no. 11, pp. 1928-1935, 2010.

[14] K. Guo, N. X. Kang, Y. Li et al., "Regulation of HSP27 on NF- $\kappa \mathrm{B}$ pathway activation may be involved in metastatic hepatocellular carcinoma cells apoptosis," BMC Cancer, vol. 9, article 100, 2009.

[15] H. Ye, A. Wang, B.-S. Lee et al., "Proteomic based identification of manganese superoxide dismutase 2 (SOD2) as a metastasis marker for oral squamous cell carcinoma," Cancer Genomics and Proteomics, vol. 5, no. 2, pp. 85-93, 2008.

[16] A. Glen, C. S. Gan, F. C. Hamdy et al., "ITRAQ-facilitated proteomic analysis of human prostate cancer cells identifies proteins associated with progression," Journal of Proteome Research, vol. 7, no. 3, pp. 897-907, 2008.

[17] R. Tom, T. Lauren, M. Damien, B. S. Lee, and R. V. Benya, "Consequence of gastrin-releasing peptide receptor activation in a human colon cancer cell line: a proteomic approach," Journal of Proteome Research, vol. 5, no. 6, pp. 1460-1468, 2006.

[18] K. W. Michael, V. D. Leroi, S. Andreas et al., "Differential protein expressions in renal cell carcinoma: new biomarker discovery by mass spectrometry," Journal of Proteome Research, vol. 8, no. 8, pp. 3797-3807, 2009.

[19] Y. Suminami, S. Nagashima, A. Murakami et al., "Suppression of a squamous cell carcinoma (SCC)-related serpin, SCC antigen, inhibits tumor growth with increased intratumor infiltration of natural killer cells," Cancer Research, vol. 61, no. 5, pp. 1776-1780, 2001.

[20] C. Katagiri, J. Nakanishi, K. Kadoya, and T. Hibino, "Serpin squamous cell carcinoma antigen inhibits UV-induced apoptosis via suppression of c-JUN NH2-terminal kinase," Journal of Cell Biology, vol. 172, no. 7, pp. 983-990, 2006.

[21] K. I. Hashimoto, T. Kiyoshima, K. Matsuo, S. Ozeki, and H. Sakai, "Effect of SCCA1 and SCCA2 on the suppression of TNF- $\alpha$-induced cell death by impeding the release of mitochondrial cytochrome $\mathrm{c}$ in an oral squamous cell carcinoma cell line," Tumor Biology, vol. 26, no. 4, pp. 165-172, 2005.

[22] Q. Santina, V. Laura, T. Cristian et al., "SERPINB3 induces epithelial-mesenchymal transition," Journal of Pathology, vol. 221, no. 3, pp. 343-356, 2010.

[23] K. Seung-Wook, C. Kyounga, K. Chang-Hoon et al., "Proteomics-based identification of proteins secreted in apical surface fluid of squamous metaplastic human tracheobronchial epithelial cells cultured by three-dimensional organotypic air-liquid interface method," Cancer Research, vol. 67, no. 14, pp. 6565-6573, 2007.

[24] S. Tan and Z. Xiao, "Nasopharyngeal carcinoma," International Journal of Oncology, vol. 34, no. 12, pp. 904-907, 2007.

[25] K. Arai, T. Teratani, and R. Nozawa, "Immunohistochemical investigation of S100A9 expression in pulmonary adenocarcinoma: S100A9 expression is associated with tumor differentiation," Oncology Reports, vol. 8, no. 3, pp. 591-596, 2001.

[26] K. Arai, T. Yamada, and R. Nozawa, "Immunohistochemical investigation of migration inhibitory factor-related protein (MRP)-14 expression in hepatocellular carcinoma," Medical Oncology, vol. 17, no. 3, pp. 183-188, 2000.

[27] Y. Ito, K. Arai, Ryushi et al., "S100A9 expression is significantly linked to dedifferentiation of thyroid carcinoma," Pathology Research and Practice, vol. 201, no. 8-9, pp. 551-556, 2005.
[28] M. Ichikawa, R. Williams, L. Wang, T. Vogl, and G. Srikrishna, "S100A8/A9 activate key genes and pathways in colon tumor progression," Molecular Cancer Research, vol. 9, no. 2, pp. 133148, 2011. 


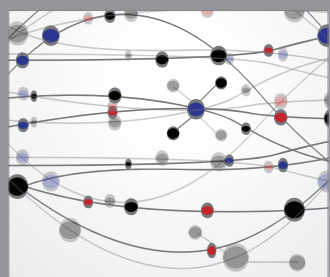

The Scientific World Journal
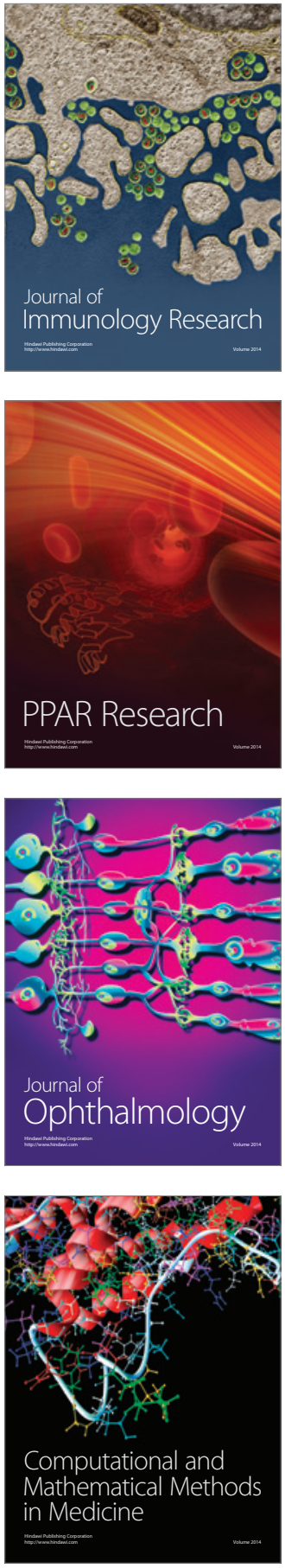

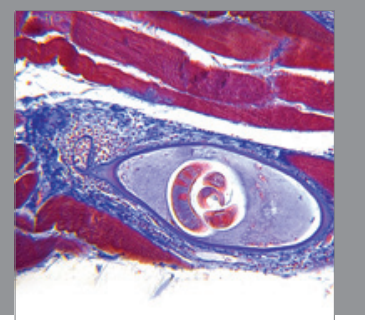

Gastroenterology

Research and Practice
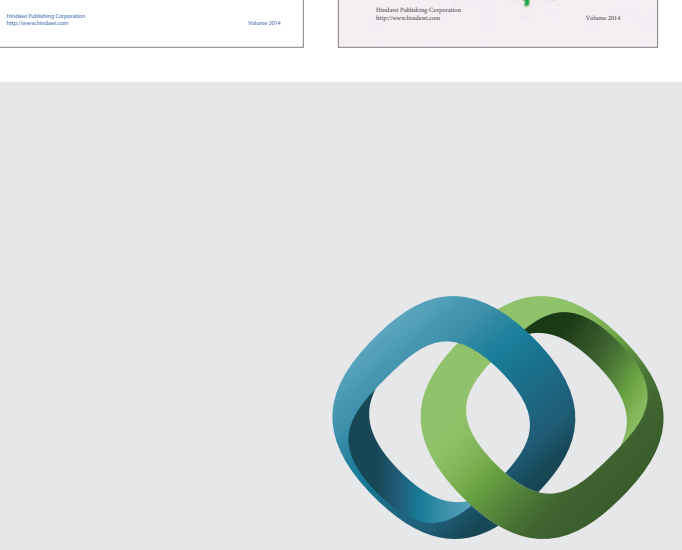

\section{Hindawi}

Submit your manuscripts at

http://www.hindawi.com
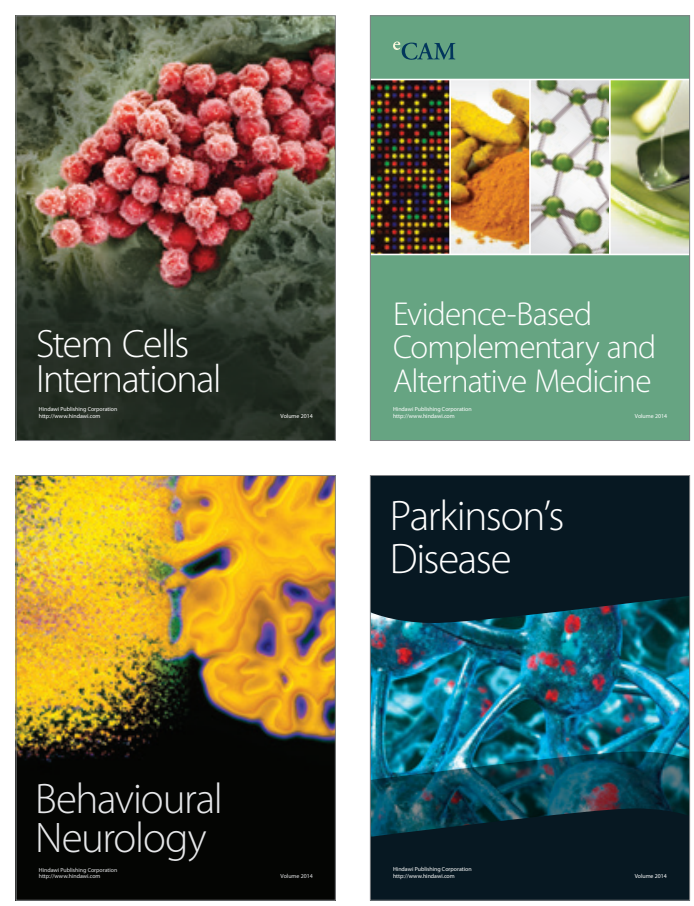

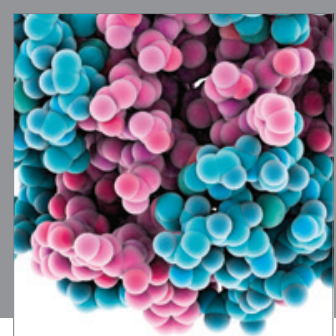

Journal of
Diabetes Research

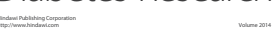

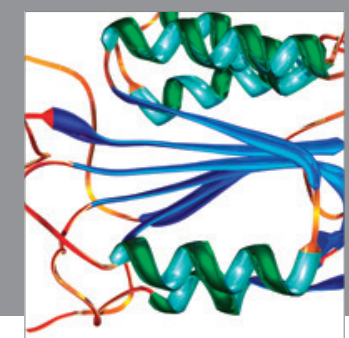

Disease Markers
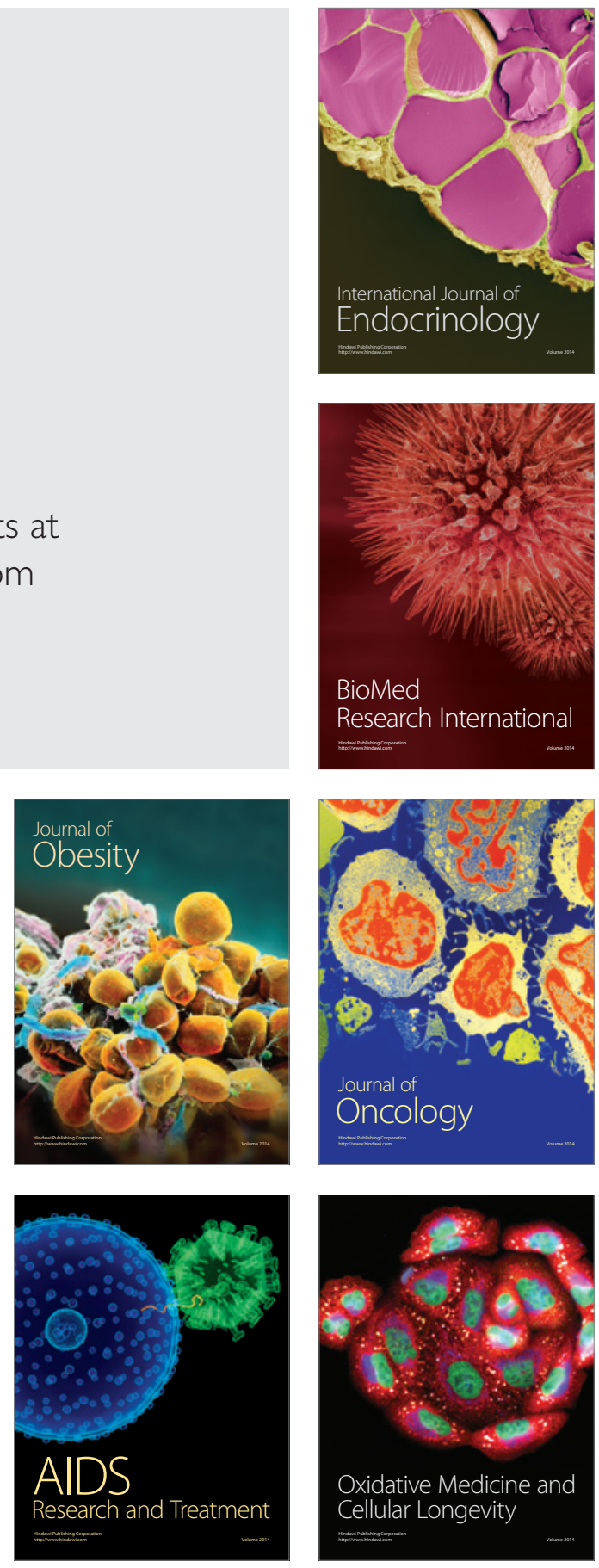